\title{
SOBERANIA NACIONAL E IMÓVEIS RURAIS
}

\author{
Tarcisio Miguel Teixeira ${ }^{1}$ \\ Dorita Ziemann Hasse ${ }^{2}$ \\ Luiz Roberto Prandi ${ }^{3}$
}

TEIXEIRA, T. M.; HASSE, D. Z.; PRANDI, L. R. Soberania nacional e imóveis rurais. Rev. Ciênc. Juríd. Soc. UNIPAR. Umuarama. v. 17, n. 2, p. 261-285, jul./ dez. 2014.

RESUMO: A globalização, fenômeno que surgiu ao final do século XX, como resultado do dinamismo do sistema capitalista ao gerar novos e grandes mercados, propicia uma integração global nos aspectos políticos, sociais, culturais e econômicos. Sendo esta última faceta determinante para o sistema. Neste contexto, observa-se a formação de conglomerados de capital apátrida, sempre solícitos à investimentos nos países em desenvolvimento. Estes investimentos buscam assumir a coordenação a jusante e a montante das cadeias produtivas, especialmente no agronegócio. A Soberania nos moldes atuais, segundo os defensores destes investimentos, é um obstáculo à entrada de capitais estrangeiros para compra de terras agrícolas e pode comprometer o desenvolvimento brasileiro, prejudicando a geração de emprego e renda. Todavia, argumentações econômicas e jurídicas contundentes, comprovam a não necessidade da entrada de capitais para investimentos na forma de compra de terras agrícolas. O presente trabalho busca apresentar as justificativas dos defensores da flexibilização sobre a compra de terras agrícolas no Brasil por capital estrangeiro e fundamentar uma contraposição econômica e jurídica a esta flexibilização.

PALAVRAS-CHAVE: Globalização; Soberania; Compra de terras agrícolas.

\section{INTRODUÇÃO}

A Soberania e sua preservação foram a força motriz para o início deste trabalho. Distante de ser uma discussão pejorativamente platônica, o tratar da Soberania é algo concreto e sua saúde e independência interferem diretamente no exercício da cidadania. A educação, o sistema de saúde funcional, o acesso

DOI: https://doi.org/10.25110/rcjs.v17i2.2014.5404

${ }^{1}$ Mestre em Agronomia (UEM) e Docente de Agronegócios e Agroecologia (IFPR Umuarama), tarcisio.teixeira@ifpr.edu.br

${ }^{2}$ Mestre em Direito Processual (UNIPAR) e Docente de Filosofia e Ciência Política (UNIPAR), dorita@unipar.br

${ }^{3}$ Doutor em Ciências da Educação e Professor Titular da Universidade Paranaense (UNIPAR), prandi@unipar.br 
ao trabalho, desenvolvimento sustentável e todos demais direitos que cabem aos componentes de uma nação estão na dependência de sua Soberania, ou seja, na sua autogovernabilidade.

Frente a um crescimento exponencial do capitalismo mundial e inexorável invasão dos recursos naturais dos países pobres e em desenvolvimento, é improvável que o Brasil passe incólume por tal processo. Como grande fornecedor de matéria-prima para o mercado mundial, principalmente nos segmentos ligados ao agronegócio, o Brasil é observado e desejado por fundos de investimentos e outras nações que sonham aqui implantar bases produtivas para seus mercados internos e mundiais.

O raciocínio destas instituições na tessitura capitalista pode ser sintetizado no seguinte questionamento: por que é necessário ser um comprador da soja brasileira se podemos "comprar" o Brasil e lá termos a nossa produção?

Todavia, a resposta satisfatória a tais fundos e nações perpassa a desconstrução de nossa Soberania. Faz-se necessário paulatinamente e sub-repticiamente produzir uma mentalidade brasileira que acredite ser a Soberania, nos moldes atuais, algo ultrapassado e que, inclusive, elanguesce o tão prolatado desenvolvimento econômico.

Neste aspecto os teóricos da desconstrução procuram areolar o desenvolvimento econômico como a embarcação noélica e demonizar a concretização da sã Soberania como o desencadeador do fim dos tempos.

Trata-se de construir um desejo popular de romper com a proteção da Soberania para buscar recursos econômicos externos.

Este projeto é concretizado com a disseminação de opiniões científicas e políticas por personalidades de renome nacional. Tendo como sustentáculo a autoridade acadêmica e representativa destas figuras, confere-se à população a segurança necessária para concordar e até mesmo labutar pelas restrições à Soberania.

O artigo contrapor-se-á a esta tentativa de sabotagem à Soberania. Esta contraposição percorrerá a análise de uma destas hipóteses desconstrutivistas, o confrontamento entre Soberania e globalização, a observação do desenrolar da ocupação de terras pelo sistema capitalista e o desempenho do agronegócio brasileiro. Objetivando, com estas apreciações, confluir para uma defesa constitucional da Soberania do Estado brasileiro.

\section{A EXEGESE}

O estudo de textos bíblicos é uma das tarefas mais árduas para o homem. $\mathrm{O}$ estudioso das sacras escrituras deve aprimorar-se em diversos recursos intelectuais, como: geográficos, históricos, linguísticos, etc. O simples conhecer 
bíblico é deveras trabalhoso. Todavia, mais complexo ainda constitui-se a sua interpretação, ou seja, tirar de dentro das escrituras a ditosa mensagem de hoje.

Libanio e Murad (2005, p. 217) reforçam que o exegeta lança mão de instrumental científico para captar o significado da letra da Escritura. Com a devida humildade em relação aos doutos teólogos, acrescenta-se à sua definição a necessidade de capturar o verdadeiro significado da letra sacra.

Todavia, no exercício da exegese, diante de uma falta de preparo ou má intenção, verdadeiras atrocidades já foram cometidas. Os registros históricos quanto às estas falhas incomodam aos cristãos constantemente.

A má interpretação pode não refletir a verdade para a vida das pessoas presentes. De forma mais grave pode trazer prejuízos incalculáveis aos fiéis que seguiram tais ideias como ordem de prática e fé.

Resumindo: o intérprete de um texto pode cometer erros pelos mais variáveis motivos e também pode interpretar de forma equivocada ou deturpada por interesses pessoais. Conduzindo, assim, os leitores e ouvintes a acreditar no que não é verdade e praticar o que não é realmente bom para as suas vidas.

Esta interpretação equivocada ou deturpada não é ostentação unicamente da Teologia, também as ciências jurídicas e econômicas podem ser vituperadas por estas exegeses recheadas de erros ou segundas intenções.

Entretanto, nos meios jurídico e econômico, a maior frequência obtém-se nas segundas intenções. Aliás, no mundo midiático a serviço do sistema atual "Não há produção excessiva de informação, mas de ruídos. Existem os fatos, as notícias são interpretações destes fatos. Como as grandes agências de notícias pertencem às grandes empresas, os acontecimentos são analisados de acordo com os interesses pré-determinados" (TENDLER, 2006).

$\mathrm{Na}$ análise de Milton Santos, eminente geógrafo brasileiro, podemos encontrar a seguinte afirmação, "Muitos dos economistas que escrevem em jornais publicam diariamente o desejo das empresas das quais são consultores" (TENDLER, 2006).

Sobre o sistema financeiro mundial, Santos acrescenta:

a informação é o grande instrumento da grande finança. A informação é o grande instrumento do processo de globalitarismos e produção de novas formas totalitárias de vida, mas que, manejada por pequenos grupos de forma inteligente, produzem exatamente o efeito oposto (TENDLER, 2006).

Com este prisma de observação, torna-se evidente um desejo manipulativo por detrás destas leituras produzidas por intelectuais comprometidos com o sistema financeiro. Recorrendo a um velho ditado "Quem usa o texto sem o contexto, quer um pretexto", ou seja, são produzidas informações elevadas ao 
título de verdades, porém, nem todos os contornos das mesmas são apresentados à sociedade que as receberá.

Portanto, as análises econômicas e jurídicas divulgadas na mídia serviçal como o caminho a ser percorrido pela nação, podem tornar-se, ao fim da estrada, um báratro e despejar toda a sociedade brasileira no desastre econômico.

\section{A SOBERANIA}

Segundo a professora Liziane Paixão Oliveira (2005) a globalização pode não somente contrapor-se à Soberania, mas o encontro de tais realidades pode implicar na transformação do conceito de Soberania.

Sendo esta uma tentativa já observada no texto de mídia popular que se analisará mais arraigadamente neste artigo.

Portanto, para dar continuidade às análises, encaminhar-se-á inicialmente uma definição de Soberania. Mais precisamente uma tentativa de definição, pois é assunto de tal monta que já ocupou muitos tratados de grandes juristas, filósofos e cientistas políticos.

Para Maluf (1988, p. 45), "Soberania é uma autoridade superior que não pode ser limitada por nenhum outro poder".

O mesmo autor cita Clóvis Bevilácqua que leciona, "por soberania nacional entendemos a autoridade superior, que sintetiza politicamente, e segundo os preceitos de direito, a energia coativa do agregado nacional" (MALUF, 1988, p. 46).

A definição de Maluf é de posição, ou seja, posiciona a Soberania delimitando as outras formas de poder, endógenas ou exógenas.

Bevilácqua apresenta uma Soberania funcional, pois lhe confere o potencial de atuar a partir de sua energia coativa, ou seja, exercer a função de coação sobre a massa nacional para que executem a sua determinação.

Bodin (1993) contribuiu com esta tarefa atribuindo características à Soberania. "La souveraineté est la puissance absolue et perpétuelle d'une République". A definição de Maluf (1988) deságua na primeira característica citada por Bodin, pois sendo absoluta, está acima de qualquer outra forma manifesta de poder político.

A segunda característica de Bodin traz a questão da temporalidade ao poder soberano. Ela deve percorrer por qualquer período histórico do Estado, pois uma limitação temporal eclipsaria seu absolutismo. Bastaria passar o tempo e fatos históricos trazerem novidades à questão e encontrar-se-ia justificativas para eliminar ou mutar a Soberania.

Os modernos teóricos do tema não são escravizados pela aparente rigidez da definição de Bodin e produzem uma nova visão de Soberania. 
Para Miguel Reale (2000) o exercício da Soberania possui limitações geográficas, pois cada Estado deve restringir-se ao seu território, e éticas, devendo acatar as normas da conveniência.

Também Rezek (2008) estabelece limites à Soberania dos Estados modernos. Este cerceamento ocorre devido as suas relações internacionais, pois a Soberania de um Estado deve respeitar a do outro. Todavia, uma Soberania não deve impor-se à outra, elas igualam-se, não havendo assim entidade superior desta natureza.

Enquadrando-se perfeitamente no objeto deste artigo o esclarecimento de Reale (2000) acerca da titularidade da Soberania. Segundo este mestre

a soberania é do Estado, sub specie juris, mas é do povo, pertence à sociedade como fato social, de sorte que não podem os poderes que nela se contêm ser exercidos com opressão do povo. Quando a opressão existe, há apenas aparência de juridicidade, há forma jurídica ilusória, que se respeita por ser força e não por ser Direito, isto é, que se respeita enquanto não haja força capaz de se opor à usurpação, restabelecendo a unidade essencial que deve existir entre a soberania social e a soberania jurídica, entre a opinião pública e o Estado, entre o processo das normas e dos atos jurídicos e o desenvolvimento e as aspirações da vida coletiva (REALE, 2000, p. 144).

As formas sub-reptícias de apresentar teorias políticas e econômicas com o intuito de desmantelar a Soberania nos países em desenvolvimento poderiam ser definidas em Miguel Reale pela denominação de "forma jurídica ilusória". Volvendo ao tratamento inicial do texto, sobre uma exegese a serviço de algum interesse, pode-se perceber que este fato também está a ocorrer nas possíveis manipulações do conceito moderno de Soberania.

É um desvio da real virtude da Soberania, pois o fadário correto da mesma é atender ao povo, pois a ele pertence a sua natureza social.

Recomenda ainda o ilustre jurista que a Soberania da Nação e do Estado não se tornem opostos, mas que "a segunda seja a expressão da primeira, de sorte que o poder se exerça cada vez mais na forma do Direito" (REALE, 2000). Assim, qualquer tratar de Soberania não deve desconectar os âmbitos social e jurídico que a formam. O respeito ao componente humanitário, em momento algum, pode ser deixado de lado nas composições e pressões que a Soberania venha a sofrer pelo processo de globalização.

Para solidificar esta dependência da Nação ao trabalhar com a Soberania, citemos mais uma vez Miguel Reale (2000): "não há poder que não tenha sua fonte na coletividade". Sendo a sua coletividade a sua origem, a seu serviço deve estar. 


\section{A DESCONSTRUÇÃO DA SOBERANIA}

Em uma observação mais cuidadosa é perceptível o rodar de engrenagens que visam desconstruir a Soberania Nacional. O intuito do grande capital internacional e de nações ricas é retirar qualquer impedimento para o seu avançar sobre os recursos naturais dos países pobres e não desenvolvidos.

Vários são os engenhos utilizados para atingir este objetivo. Destaca-se neste trabalho o uso da mídia popular escrita, como meio de propagação de ideias neoliberais disfarçadas de baluartes do desenvolvimento econômico e do pleno emprego.

A ideia principal desta tática é transferir aos habitantes dos países a serem invadidos pelo capital internacional, que a Soberania é algo fora de moda, démodé. Tornou-se, inclusive um estorvo tal, que os países desenvolvidos a flexibilizaram razoavelmente.

Não é esta toda a verdade. O diplomata Celso Amorim declarou no documentário "O mundo global visto do lado de cá":

agora esta história de que os Estados Nacionais estão diminuindo de importância é uma história da carochinha que os países ricos nos contam porque o Estado, por exemplo, Nacional Americano vai muito bem. Inclusive, bem do ponto de vista de força do Estado com gasto militares como nunca houve antes. Com empenho direto, vamos dizer assim, dos agentes comerciais, do governo americano para defender os interesses das empresas norte-americanas. O que é normal, aliás. Então, eles nos dizem: o Estado não tem importância, quer dizer não estou dizendo eles norte-americanos, mas estes pensadores da globalização muitas vezes nos dizem isto. Isto é o que, digamos, crer quem quer ser enganado (TENDLER, 2006).

Estes países ricos fortalecem suas Soberanias diante do processo de globalização porque sabem das consequências nefastas que esta pode ocasionar as suas economias.

Segundo Didone (1999), "os Estados Nacionais são cada vez mais necessários e ativos, mas incapazes de dar conta dos novos desafios pela economia mundial". Percebe-se pela crise econômica mundial em erupção constante que mesmo os países ricos não são imunes ao poder destroçante da globalização econômica. Que dirá do Brasil, que recente saiu da "Unidade de Terapia Intensiva" da economia.

Também Held e Macgrew defendem esta teoria em que a Soberania encontra-se ameaçada pelo processo de globalização. Os Estados não têm poder para contrapor-se aos ditames da economia global. "Os processos econômicos, 
ambientais e políticos regionais e globais redefinem profundamente o conteúdo das decisões nacionais" (OLIVEIRA, 2005).

Para o caso em tela, aquisição de imóveis rurais por estrangeiros e equiparados, deve-se olhar também os exemplos externos. O próprio Consultor Geral da União, Ronaldo Jorge Araujo Vieira Junior, no Parecer CGU/AGU $\mathbf{N}^{\mathbf{0}}$ 01/2008 - RVJ, cita os casos do México e Estados Unidos da América que produziram em suas legislações normas mais rígidas do que as do Brasil. Cita-se o detalhamento feito pelo Consultor sobre a restrições estadunidenses.

Pela legislação federal é obrigação do estrangeiro elaborar relatórios das aquisições realizadas ao Secretário de Agricultura. Em Nova York, o estrangeiro deve naturalizar-se americano para possuir propriedade rural. Na Virgínia, permite-se apenas a posse, não a propriedade ao estrangeiro que seja residente há mais de cinco anos. Em Iowa, as terras não destinadas à agricultura podem ser negociadas livremente; as terras destinadas à agricultura não podem pertencer a pessoas, físicas ou jurídicas, não residentes. No Missouri, as terras não destinadas à agricultura podem ser negociadas livremente, as terras destinadas à agricultura não podem pertencer a estrangeiros. Caso estrangeiros venham a ser proprietários de terras agrícolas, o Estado dá dois anos para que sejam negociadas com nacionais, caso não sejam, vão a leilão público (BRASIL, 2012b, p. 566).

Percebe-se claramente, ao comparar as normativas norte-americanas com as equivalentes do Brasil, que o nosso sistema de proteção ao solo pátrio é mui singelo e carregado de liberalidade, mesmo com o novo Parecer aprovado. Também é transparente o quanto a Soberania, neste caso Soberania Econômica, é protegida pelo Estado Norte-americano.

Conclui-se que a globalização é uma ferramenta extremamente poderosa de dominação, mas com contornos de difícil limitação, podendo atingir até mesmo as nações ricas que encabeçam o processo. Uma vez disparado o gatilho, a globalização avança em todos os sentidos e é homogênea em seu tratamento, fazendo vítimas em ambos os lados da "balança" econômica.

Daí entender-se porque os propagadores da globalização a "venderem" como salvadora para os países pobres e recomendarem a desvirtuação de sua Soberania. Todavia, para si, a Soberania deve ser preservada e até mesmo fortalecida para o embate com os processos globalizantes. 


\section{A SOBERANIA E A COMPRA DE IMÓVEIS RURAIS POR CAPITAL ES- TRANGEIRO NO BRASIL}

Exemplos concretos deste processo de rechaçar a Soberania em prol da globalização estão ocorrendo no Brasil atual. A questão transita pela compra de terras por capital estrangeiro e pela tentativa de articulistas políticos e econômicos em demonstrar um caráter absolutamente benéfico deste processo para $\mathrm{o}$ povo brasileiro.

Dispostos em revistas e jornais de grande circulação e utilizando de técnicas interpretativas, as argumentações a favor da globalização, em seu desdobramento aquisição de terras brasileiras, são apresentadas como fenômeno imprescindível para o desenvolvimento socioeconômico do país (NÓBREGA, 2012; ROSENFIELD, 2010).

Relembrando o geógrafo Milton Santos, já citado anteriormente, que a opinião do grande sistema midiático atende as necessidades das instituições para quem prestam serviços.

Entre as defesas da liberalização de vendas de terra ao capital estrangeiro é citado o escritor americano Henry Kissinger. As citações são encaixadas dentro de um contexto para dar-lhes um significado que atenda as expectativas do articulista.

Em Nóbrega (2012) extrai-se que as "normas internacionais de direitos humanos prevaleceram sobre as prerrogativas tradicionais de governos soberanos" (KISSINGER [19-?] apud NÓBREGA, 2012). O ex-ministro interpreta que o autor está criticando com estas palavras a exacerbação da Soberania nos estados latino-americanos. Tanto que esta proteção extrapolada de tais Estados estaria prejudicando o crescimento econômico dos mesmos e no caso do Brasil, impedindo que nós cumpríssemos com a nossa sagrada missão de produzir comida para o mundo ${ }^{4}$.

Esta é uma possível interpretação, entretanto, existem outras. Por exemplo, Kissinger pode estar se referindo aos Governos totalitários e ditatoriais que ainda comandam alguns países asiáticos e árabes. Nestes países a Soberania do Estado está sujeita às vontades de um ditador e este, na maioria das vezes, utiliza tal poder instituído para satisfazer suas vontades e perpetuação no poder, mesmo que isto custe o sacrifício e a penalização injusta de seu povo. Assim, seria justo que normas internacionais de direitos humanos, realmente, sobreponham-se às prerrogativas de Soberania destes governos. Salientando a visão de Miguel Reale, tal Soberania perde sua legitimidade ao oprimir a nação.

Outra interpretação também deve ser feita. O senhor Henry Kissinger

${ }^{4} \mathrm{O}$ mundo está loteado pelo capital internacional: China produção de eletrônicos e industrializados e o Brasil com a função de produzir alimentos. 
foi conselheiro para política estrangeira do governo americano durante muitos mandatos presidenciais, sendo considerado o mentor das políticas externas dos mesmos. Sobre a sua atuação paira uma verdadeira nuvem negra, pois ele é acusado por críticos de instruir os presidentes americanos de praticarem relações econômicas e militares nada democráticas com muitos países (HITCHENS, 2002). Assim, qual é o verdadeiro interesse do senhor Kissinger em fazer tais afirmações, estaria ele interessado nos direitos humanos de países estrangeiros, o que contradiz algumas de suas práticas diplomáticas, ou simplesmente em induzir a abertura dos países com economia política de base socialista, a abrirem suas fronteiras para o investimento do capitalismo?

O filósofo Bruno Costa Simões (2012) em seu texto, A Soberania Revisitada: Carl Schmitt, Foucault e a questão do poder, salienta que atualmente a autoridade política dos Estados independentes tem sido posta em xeque por pressões econômicas, disputas territoriais ou violações dos direitos humanos. Reforçando a nossa hipótese de que o questionamento da viabilidade da Soberania brasileira tem outros interesses.

Também podemos analisar que no texto, Nóbrega (2012), faz uso implícito do capitalismo como um sistema econômico justo e distribuidor das riquezas geradas. Esta versão capitalista do século XXI é batizada por alguns pensadores como Modelo Econômico Neocapitalista e esse novo sistema faz um esforço para corrigir os erros econômicos das outras versões. O princípio econômico basilar deste modelo é constituído sob a ótica do ótimo de Pareto, onde os interesses do capital e das pessoas devem atingir o equilíbrio (DANI, 2010). Porém, a concentração é algo implícito ao sistema capitalista, assim atingir um equilíbrio de distribuição de forças e renda no funcionamento do capitalismo parece incongruente (BAUMAN, 2009).

Esta interpretação de Bauman (2009) mostra o capitalismo como um sistema com uma razão perversa de funcionamento. Neste, às pessoas são concedidos direitos de galgarem maiores rendas e melhores posições na pirâmide de classificação social (passarem para a classe média). Entretanto, estas pessoas pagam um preço alto por esta passagem de classe. Maior número de horas trabalhando, muitos cursos de preparação e total instabilidade no trabalho.

Não obstante a todo esse sacrifício as pessoas continuam a ser posicionadas na periferia do sistema. Atuam como engrenagens e continuam isoladas das decisões mais cruciais para a sociedade. Esta teorização é posta de forma muito esclarecedora por Toyoda ao tratar do poder em Foucault:

Com relação à dinâmica desse poder, caracteriza-se como includente-excludente. Inclusivo no sentido de cooptar ou inserir o sujeito no sistema capitalista, seja como produtor (trabalhador) e/ou como con- 
sumidor, e ao mesmo tempo o excluindo do círculo imediato de poder, não participando no processo de decisões, colocado à margem como parte das engrenagens dessa "máquina" de poder, utilizando-se o termo foucaultiano (TOYODA, 2010, p. 351).

No mesmo artigo o autor elucida o sofisma que se apresenta a sociedade, enrustida de distribuição de oportunidades e justiça social. "Conseguiu-se assim criar uma falsa ideia de empoderamento dos indivíduos, quando na verdade instalavam-se mecanismos sutis de dominação, num processo de interpenetração entre o Estado e o poder econômico do Capital" (TOYODA, 2010, p. 349).

A real pretensão do capitalismo na globalização não é a de distribuir renda, justiça ou permitir a realização do individuo frente a uma Soberania retrógada, mas sim desenvolver uma forma de dominação que o torne o menos visível possível. Todavia, maximizando "o controle sobre cada sujeito obtendo, por extensão, a sua máxima produção ou contribuição ao sistema econômico (TOYODA, 2010, p. 345).

São ofuscantes estas verdades sobre o sistema capitalista e suas contradições. Portanto, rompe-se as bases teóricas aos que pretendem analisar o desenvolvimento econômico mundial a partir de um conceito apriorístico de uma globalização econômica justa e, sempre, portadora das boas novas do desenvolvimento.

Os países em desenvolvimento e pobres estão, no processo de globalização, frente a uma nova sub specie de criatura dominadora, o capital apátrida. Não se tem mais aquela figura de um Estado hegemônico e dominador. Estes Estados continuam atuantes no cenário mundial, mas agora eles também estão a serviço do capital.

Toyoda também expressa esta mudança em seu trabalho:

De certo modo, o que se tem então é a substituição do "Leviatã" representado pela figura do Estado, nos termos da construção simbólica de Hobbes, por outro ser igualmente poderoso que, como o monstro bíblico, é dotado de força atemorizante em sua onipotência ante a fragilidade dos sujeitos, ou seja, o Capital (TOYODA, 2010, p. 346).

Com estes argumentos é plausível concluir que o capitalismo não evoluiu para uma forma amena e repleta de benesses aos países periféricos.

A globalização é uma abertura de oportunidades para todos os países, mas aos países periféricos as oportunidades não serão as mesmas, pois não lhes cabem decidir sobre o próprio futuro e a forma que participarão deste processo.

Quando estes países periféricos são munidos de mecanismos protetores que impeçam o avançar dominador do capital apátrida, infelizmente, dentro de 
suas próprias fileiras, serão acionados agentes prontos a desconstruir estes mecanismos.

Os textos citados (NÓBREGA, 2012; ROSENFIELD, 2010) e outros, trazem fortes indícios que pretendem atender esta função do parágrafo anterior.

Nesta análise crítica também não se pode esquecer que o tema central é o uso econômico de nosso recurso natural, as terras. A este uso econômico, com a contribuição de Davis e Goldberg (2007), aplicamos a denominação de Agribussines, hoje Agronegócio no Brasil.

O Agronegócio no capitalismo necessita funcionar com produção em escala. Neste caso para aprimorar-se em volume produzido, aproveitamento da mão-de-obra e uso intensivo dos insumos das multinacionais, o agricultor deve praticar uma produção ultraespecializada e muito dependente da cadeia agroindustrial. A produção agrícola passa a atender a produção industrial e as características típicas do capitalismo são internalizadas pelas propriedades agrícolas. Símbolo maior deste processo de internalização é o surgimento da figura da empresa agrícola. A qual, o articulista defende que deveria receber investimentos estrangeiros e ter maior liberdade para adquirir áreas maiores de produção.

Segundo a cartilha de funcionamento capitalista, estas empresas agrícolas devem ter o seu funcionamento calcado em:

Margens de lucratividade baixas para os componentes não dominantes da cadeia de produção;

- Margens altas para o elemento dominador da cadeia de produção;

- Controle do fluxo da cadeia de produção;

- Uso eficiente e intenso de insumos industrializados exogenamente à propriedade;

- Pouca mão-de-obra;

- Formação de latifúndios;

- Exclusão do homem do campo, consequentemente, geradora do inchaço das cidades e favelas.

Será este o modelo que se quer para a agricultura brasileira? Será que a sociedade já não sofreu o bastante com este processo? Já não há concentradores de terra demais?

Uma das formas de exercer dominação dentro do agronegócio é estender as posses dos setores produtivos a montante e jusante da cadeia produtiva. É um processo denominado verticalização da cadeia produtiva.

Esta dominação aumenta substancialmente a segurança da atividade econômica da empresa. Portanto, é um desejo de todas as empresas atingirem este nível dentro dos mercados em que participam.

No caso do capital que quer investir na posse de terras no Brasil, ele está muito próximo de atingir este nível. Pois, é o mesmo capital que forma os 
fornecedores de insumos, como agrotóxicos e máquinas, e também as empresas processadoras dos produtos agrícolas, como indústrias alimentícias.

Imagine tal situação, um capital que domina os insumos, a produção agrícola e também a transformação destes produtos. A verticalização completa, com total possibilidade de controlar os preços e ofertas. Com certeza o consumidor não seria privilegiado nesta relação de poder.

Outro engodo dos adeptos da defesa da liberalização de vendas de terras agrícolas é tratar a especulação imobiliária como a única forma de provocar um mau uso da terra. Como vimos acima, estas empresas agrícolas podem ser extremamente produtivas, mas mesmo assim, refletirem poucos benefícios para os consumidores e população em geral.

Fundamentando-se na argumentação acima e observando a intensa compra de terras da região amazônica que ocorria por capital estrangeiro antes da revisão do parecer da Advocacia Geral da União (AGU), pode-se afirmar que, adotar uma teoria que solapa a Soberania nacional é estar de acordo com a formação de megalatifúndios no país e não o contrário.

Este processo de desconstrução da Soberania nacional, aparentemente, desconsidera a realidade do Agronegócio brasileiro. O país encontra-se entre os países de maior eficiência administrativa e técnica do setor produtivo agrícola. Assim, a liberação da compra de terras por capital estrangeiro como a única argumentação convincente para que os empresários estrangeiros invistam no Agronegócio brasileiro é ofensiva aos empresários brasileiros do Agronegócio.

A suposição da ineficiência dos empresários brasileiros, também se estende ao Governo brasileiro, principalmente ao seu executivo. O texto, aparentemente, desconsidera toda a estrutura econômica e administrativa utilizada no setor agrícola do país.

Como se trata de um debate econômico, a melhor forma de argumentação é o uso de resultados.

Tabela 1: Evolução da área cultivada, da produção de grãos e da produtividade do biênio 90-91 ao 10-11.

\begin{tabular}{c|c|c|c}
\hline Safras & $\begin{array}{c}\text { Área plantada } \\
\text { (milhões de ha) }\end{array}$ & $\begin{array}{c}\text { Produção } \\
\text { (milhões de ton) }\end{array}$ & $\begin{array}{c}\text { Produtividade } \\
\text { (Kg/ha) }\end{array}$ \\
\hline $90-91$ & 37,8 & 57,8 & 1.528 \\
\hline $91-92$ & 38,4 & 68,2 & 1.777 \\
\hline $92-93$ & 35,6 & 68,3 & 1.916 \\
\hline $93-94$ & 39 & 76 & 1.945 \\
\hline $94-95$ & 38,4 & 81,2 & 2.103 \\
\hline
\end{tabular}




\begin{tabular}{c|c|c|c}
\hline $95-96$ & 36,8 & 73,8 & 1.990 \\
\hline $96-97$ & 36,4 & 78,9 & 2.144 \\
\hline $97-98$ & 35 & 76,5 & 2.187 \\
\hline $98-99$ & 36,7 & 82,4 & 2.234 \\
\hline $99-00$ & 37,7 & 82,8 & 2.195 \\
\hline $00-01$ & 37,3 & 98,2 & 2.649 \\
\hline $01-02$ & 40,2 & 96,7 & 2.407 \\
\hline $02-03$ & 43,9 & 123,2 & 2.803 \\
\hline $03-04$ & 47,3 & 119,1 & 2.512 \\
\hline $04-05$ & 48,3 & 114,7 & 2.339 \\
\hline $05-06$ & 47,9 & 122,5 & 2.560 \\
\hline $06-07$ & 46,2 & 131,8 & 2.851 \\
\hline $07-08$ & 47,4 & 144,1 & 3.040 \\
\hline $08-09$ & 47,7 & 135,1 & 2.835 \\
\hline $09-10$ & 47,4 & 149,2 & 3.149 \\
\hline $10-11$ & 48,8 & 153,1 & 3.134 \\
\hline
\end{tabular}

Fonte: Brasil (2012)

Os dados (TABELA 01) comprovam que a nossa produtividade, índice técnico de análise, muito utilizado, têm melhorado de forma extraordinária.

O Brasil apresenta índices de desenvolvimento agrícola acima da média mundial, de acordo com o estudo da Organização para Cooperação e Desenvolvimento Econômico (OCDE), feito em 2011. O País também lidera a produtividade agrícola na América Latina e Caribe e tem crescimento médio de 3,6\% ao ano (BRASIL, 2012a).

Assim, pergunta-se: o país e seus empresários agrícolas administram uma agricultura capenga que precisa de investimentos estrangeiros da venda de suas terras para se tornar competitiva? Não basta o retorno que o setor propicia com a comercialização de seus produtos? 
Tabela 2: Comparação dos saldos da balança comercial do Agronegócio e dos outros setores da economia (US\$ bilhões) Brasil, 1995 a 2010.

\begin{tabular}{c|c|c|c}
\hline \multirow{2}{*}{ Anos } & \multicolumn{2}{|c|}{ Setores econômicos } & \multirow{2}{*}{ Saldo comercial } \\
\cline { 2 - 3 } & Agronegócios & Outros setores & \\
\hline 1995 & 8,3 & $-11,7$ & $-3,4$ \\
\hline 1996 & 8,5 & $-14,0$ & $-5,5$ \\
\hline 1997 & 10,3 & $-17,7$ & $-7,4$ \\
\hline 1998 & 10,6 & $-16,9$ & $-6,3$ \\
\hline 1999 & 13,4 & $-14,6$ & $-1,2$ \\
\hline 2000 & 14,8 & $-13,8$ & 1,0 \\
\hline 2001 & 19 & $-16,4$ & 2,6 \\
\hline 2002 & 21 & $-16,0$ & 5,0 \\
\hline 2003 & 25,8 & $-1,0$ & 24,8 \\
\hline 2004 & 34,1 & $-0,4$ & 33,7 \\
\hline 2005 & 38,507 & 6,4 & 44,9 \\
\hline 2006 & 42,769 & 3,7 & 46,5 \\
\hline 2007 & 49,701 & $-9,7$ & 40,0 \\
\hline 2008 & 59,987 & $-35,3$ & 24,7 \\
\hline 2009 & 54,887 & $-29,6$ & 25,3 \\
\hline 2010 & 63,054 & $-42,8$ & 20,3 \\
\hline
\end{tabular}

Fonte: Brasil (2012)

Também é possível perceber (TABELA 02) que o agronegócio, mesmo com uma Soberania dita démode, tem sido o responsável por manter a balança comercial positiva. Fato responsável por diminuir sensivelmente o Risco-Brasil e atrair investimentos estrangeiros.

Outra forma de enfraquecer a Soberania neste tópico, venda de terras ao capital apátrida, é o desarrazoar o Parecer CGU/AGU No 01/2008 - RVJ. Rosenfield (2010) cita "que se tratava de uma questão juridicamente pacificada, segundo todo um ordenamento constitucional e legal". Ora, que ordenamento jurídico é este? O posicionamento equânime das empresas brasileiras com controle estrangeiro, às empresas brasileiras, também foi feito por outro parecer da AGU, o Parecer n ${ }^{\circ}$ GQ - 22, de 1994, de autoria de Geraldo Quintão. Questiona-se: para liberação de vendas de terras, o parecer é uma forte justificativa jurídica, entretanto, para coibi-la é totalmente ineficiente?

Neste estágio salienta-se o cuidado necessário com o contato que se 
tem com textos de grandes e populares nomes dos meios científico, econômico e políticos. A relação que as pessoas comuns guardam com figuras intelectuais ou que já estiveram em cargos importantes, pode resultar em uma assimetria de informações. Fato que, nas relações econômicas, propiciam um desequilíbrio na satisfação de seus interesses.

Segundo as palavras do professor Paulo Marcelo M. Teixeira da Universidade Estadual do Sudoeste da Bahia:

Como as pessoas possuem um conhecimento precário e incipiente sobre os aspectos da ciência e da tecnologia, como não refletem sob o impacto dessas atividades sobre a sociedade, não compreendem a linguagem da ciência, e, não dominam minimamente os códigos inerentes a esse ramo das atividades humanas, a tendência é que fiquem na dependência dos técnicos, cientistas, pesquisadores, médicos, economistas, etc. Aí realmente, a ciência passa a ditar o que é certo e errado, como se fosse um evangelho que dogmaticamente não pode ser questionado (TEIXEIRA, 2006, grifo nosso).

Portanto, a população de uma forma geral desconhecedora de noções básicas de economia e de legislação, pode ser induzida pelo pensamento articulado e convincente apresentado em artigos populares.

Em Nóbrega (2012) faz-se brilhar os olhos dos que desejam crescimento econômico e emprego a frase: "O relevante é crescer de forma sustentada e ampliar o bem-estar dos brasileiros. Pouco importa a nacionalidade do agente desse processo". Porém, este capital sem nacionalidade importar-se-á com o bem-estar dos brasileiros?

Aparentemente, lança-se uma campanha para deixar o brasileiro sôfrego em ceder suas terras produtivas e, sim, muito valorosas para o capital estrangeiro.

Quanto a extensão das propriedades rurais adquiridas por pessoas físicas estrangeiras, a regulamentação é por meio da Lei n 5.709 de 07 de outubro de 1971. Esta Lei foi regulamentada pelo Decreto nº 74.965 de 1974.

Em sua literalidade, diz:

Art. $1^{\circ}$ - O estrangeiro residente no País e a pessoa jurídica estrangeira autorizada a funcionar no Brasil só poderão adquirir imóvel rural na forma prevista nesta Lei.

$\S 1^{\circ}$ - Fica, todavia, sujeita ao regime estabelecido por esta Lei a pessoa jurídica brasileira da qual participem, a qualquer título, pessoas estrangeiras físicas ou jurídicas que tenham a maioria do seu capital social e residam ou tenham sede no Exterior. 
Art. $3^{\circ}$ - A aquisição de imóvel rural por pessoa física estrangeira não poderá exceder a 50 (cinquenta) módulos de exploração indefinida, em área contínua ou descontínua.

$\S 3^{\circ}$ - O Presidente da República, ouvido o Conselho de Segurança Nacional, poderá aumentar o limite fixado neste artigo.

Os módulos de exploração indefinida são classificados pelo INCRA na Instrução Especial INCRA n ${ }^{\circ}$ 5-A, de 1973, que deve ser interpretado a partir da Instrução Especial INCRA nº 50, de 1997.

Segundo a tabela que consta em INCRA 5/73, os Módulos de Exploração Indefinida (MEI) podem variar de 5 a 100 ha (classificação do Zoneamento Típico de Módulo). Portanto, multiplicando pelos $50 \mathrm{MEI}$ que são permitidos a aquisição por pessoas físicas estrangeiras de propriedades podem oscilar entre 250 ha (50 MEI X 5 ha) até 5000 ha (50 MEI X 100 ha).

Em Nóbrega (2012), sugere-se que as empresas estrangeiras ou de capital estrangeiro, somente podem adquirir propriedades de 5000 ha.

Empresas brasileiras de capital estrangeiro não podem comprar imóveis rurais além de certo limite, em torno de 5000 hectares. É o que diz parecer da Advocacia-Geral da União, aprovado por Lula em 2010. O texto se baseia em conceitos ultrapassados de soberania e em um nacionalismo démodé.

Recorrendo a completude da Lei analisemos o $\S 5^{\circ}$ do art. $7^{\circ}$ do Decreto 74.965/74:

O Presidente da República, ouvido o Conselho de Segurança Nacional, poderá aumentar o limite fixado neste artigo.

Pode-se perceber que para as pessoas físicas estrangeiras este limite pode ser ultrapassado. Porém, até este momento cita-se pessoa física e não jurídica. Encontra-se o tratamento deste item na Lei $\mathrm{n}^{\circ} 8.629$ (regulamenta os dispositivos constitucionais sobre a Reforma Agrária). Vejamos o Art. 23 desta lei:

Art. 23. O estrangeiro residente no País e a pessoa jurídica autorizada a funcionar no Brasil só poderão arrendar imóvel rural na forma da Lei n ${ }^{\circ} 5.709$, de 7 de outubro de 1971.

$\S 1^{\circ}$ Aplicam-se ao arrendamento todos os limites, restrições e condições aplicáveis à aquisição de imóveis rurais por estrangeiro, constantes da lei referida no caput deste artigo. 
$\S 2^{\circ}$ Compete ao Congresso Nacional autorizar tanto a aquisição ou o arrendamento além dos limites de área e percentual fixados na Lei ${ }^{\circ}$ 5.709, de 7 de outubro de 1971, como a aquisição ou arrendamento, por pessoa jurídica estrangeira, de área superior a 100 (cem) módulos de exploração indefinida.

Assim, segundo a Lei 5.709/71, o Decreto 74.965/74, CF/88 art. 49 e a Lei 8.629/93 as restrições quantitativas para posse de terra por estrangeiros é de 50 MEI para pessoas físicas estrangeiras e 100 MEI para pessoas jurídicas estrangeiras.

Lembrando que, com a aceitação do $\S 1^{\circ}$, Art. $1^{\circ}$, da Lei $5.709 / 71$ pela $\mathrm{CF} / 88$ a empresa estrangeira autorizada a funcionar no Brasil e nacional de capital estrangeiro controlador são tratadas igualmente.

O Decreto $74.965 / 74$ porta outras restrições às empresas estrangeiras autorizadas a funcionar no Brasil e de nacionais de capital estrangeiro controlador.

Art. $2^{\circ}$ A pessoa estrangeira, física ou jurídica, só poderá adquirir imóvel situado em área considerada indisponível à segurança nacional mediante assentimento prévio da Secretaria Geral do Conselho de Segurança Nacional.

Art. $5^{\circ} \mathrm{A}$ soma das áreas rurais pertencentes à pessoas estrangeiras, físicas ou jurídicas, não poderá ultrapassar 1/4 (um quarto) da superfície dos Municípios onde se situem comprovada por certidão do Registro de Imóveis, com base no livro auxiliar de que trata o artigo 15.

$\S 1^{\circ}$ As pessoas de mesma nacionalidade não poderão ser proprietárias, em cada Município, de mais de $40 \%$ (quarenta por cento) do limite fixado neste artigo.

Ficando claro, que a afirmação em Nóbrega (2012) não expressa o que diz o sistema normativo brasileiro para a aquisição de terras por estrangeiros.

Neste quesito convém salientar que no site oficial do INCRA, em 28 de maio de 2013, foi noticiada a implantação do Sisnate (Sistema Nacional de Aquisição e Arrendamento de Terras por Estrangeiros) em parceira com o Serpro (Serviço Federal de Processamento de Dados). Os recursos do sistema permitem a geração de relatórios e gráficos que apontam o quantitativo de estrangeiros no país e nos municípios, além do percentual de área do município ocupado por eles. O cumprimento da Lei 5.709/71 será automatizado e realizar-se-á um controle muito mais rigoroso em todo o país (BRASIL, 2013).

Quanto à Soberania, o artigo $1^{\circ}$ de Constituição Federal brasileira é 
esclarecedor para se entender o quanto ela é importante e salutar para o desenvolvimento e mantença de um Estado equilibrado com respeito ao seu povo.

Art. $1^{\circ}$ A República Federativa do Brasil, formada pela união indissolúvel dos Estados e Municípios e do Distrito Federal, constitui-se em Estado Democrático de Direito e tem como fundamentos:

I - a soberania;

A Constituição brasileira abre seus portais de Democracia com esta preocupação: Soberania.

E o inciso segundo: Qual seria ele?

$$
\text { II - a cidadania; }
$$

A Soberania é a segurança para que o governo possa propiciar a cidadania aos brasileiros.

E qual o inciso III?

$$
\text { III - a dignidade da pessoa humana; }
$$

A Soberania protege a cidadania, o exercício desta permite ao brasileiro viver com justa dignidade.

Não menos incrível, o inciso IV:

$$
\text { IV - os valores do trabalho e da livre iniciativa; }
$$

A Soberania que garante a cidadania, que permite um viver digno com trabalho valorizado acima do capital e respeitando a livre iniciativa, não permitindo que esta seja estrangulada pela especulação ou dominação da cadeia produtiva.

Portanto, o parecer da AGU vem ao encontro dos princípios constitucionais de proteção aos direitos fundamentais do brasileiro. Reforça esta afirmação o art. 172 da Constituição Federal ao afirmar: "A lei disciplinará, com base no interesse nacional, os investimentos de capital estrangeiro, incentivará os reinvestimentos e regulará a remessa de lucros". Assim, é um pressuposto constitucional o governo atuar, segundo a legislação existente e em consonância com a própria Carta Magna, no controle de investimentos estrangeiros. Mais especificamente é atuação do art. 190, que diz: "A lei regulará e limitará a aquisição ou o arrendamento de propriedade rural por pessoa física ou jurídica estrangeira e estabelecerá os casos que dependerão de autorização do Congresso Nacional”. Percebe-se, 
diante destes artigos magnos, o esvaziamento das argumentações que pretendam minar a Soberania ou mesmo, mais diretamente, favorecer a desregulamentação de compra de terras agrícolas por capital apátrida.

Os artigos tratam o Parecer CGU/AGU No 01/2008 - RVJ como uma produção de menor monta intelectual e resultado de uma pobre junção de conceitos superados. Afirma Nóbrega (2012): "O texto se baseia em conceitos ultrapassados de soberania e em um nacionalismo démodé". Lendo, atentamente, o Parecer é fácil perceber que esta crítica não se sustenta. O Consultor produziu um trabalho de 55 páginas de uma densa pesquisa legislativa e doutrinária. Interessante citar alguns dos juristas, dos quais, o parecerista lançou mão para sua construção: Anna Cândida da Cunha Ferraz ${ }^{5}$, Ribas Vieira ${ }^{6}$, Mastrodi Neto ${ }^{7}$ e Vanice Regina Lírio do Valle ${ }^{8}$, Gilmar Mendes ${ }^{9}$, Pinto Ferreira ${ }^{10}$, José Afonso da Silva $^{11}$, Modesto Carvalhosa (AS) ${ }^{12}$, Celso Ribeiro Bastos ${ }^{13}$, Oswaldo Opitz ${ }^{14}$ e Silvia Opitz ${ }^{15}$, Nelson Nery Costa ${ }^{16}$, Eros Grau ${ }^{17}$, Uadi Lammêgo Bullos ${ }^{18}$, Dal-

${ }^{5}$ Livre-docente em direito e professora da USP.

${ }^{6}$ Graduado em educação, direito e ciências sociais, doutor em direito e professor da UFRJ;

${ }^{7}$ Doutor em filosofia e teoria geral do direito pela USP.

${ }^{8}$ Doutora em Direito pela Universidade Gama Filho, Pós-doutorado em Administração pela EBAPE/ FGV.

${ }^{9}$ Ex-presidente do STF, graduado em Direito pela Universidade de Brasília(1978), mestrado em Direito pela Universidade de Brasília(1987), mestrado em Direito pela Westfälische Wilhelms - Universität Münster(1989) e doutorado em Direito pela Westfälische Wilhelms - Universität Münster(1990). Professor Adjunto da Universidade de Brasília, Docente Permanente do Instituto Brasiliense de Direito Público, Membro de corpo editorial do Direito Público (Porto Alegre), Membro de corpo editorial do Observatório da Jurisdição Constitucional, membro-permanente do Comissão Europeia para a Democracia através do Direito, Membro de corpo editorial da serie edb/saraiva e Professor Visitante da Pontifícia Universidade Católica do Rio Grande do Sul.

${ }^{10}$ Advogado, professor da faculdade de direito do Recife, membro da Academia Pernambucana de letras, senador e autor de mais de 200 livros.

${ }^{11}$ Graduado em Direito pela Universidade de São Paulo (1957) e livre-docência em direito constitucional pela mesma universidade (1969). Foi Professor Titular da Faculdade de Direito da USP de 1975 a 1995.

${ }^{12}$ Bacharel em Direito (USP-1957), Doutor em Direito (USP-1966), Professor Livre-Docente em Direito Comercial (USP-1972), Consultor Jurídico da BOVESPA (1965/1975).

${ }^{13}$ Doutor e livre docente em Direito Constitucional pela Pontifícia Universidade Católica de São Paulo e procurador do Estado de São Paulo.

${ }^{14}$ Desembargador do Estado do Rio Grande do Sul.

${ }^{15}$ Procuradora do Estado do Rio grande do sul.

${ }^{16}$ Doutor em Direito pela Universidade Lusíada de Lisboa-Portugal, Mestre em Direito pela Pontifícia Universidade Católica do Rio de Janeiro. Defensor Público de Categoria Especial da Defensoria Pública do Estado do Piauí. Professor Adjunto de Direito Público, do Departamento de Ciências Jurídicas, da Universidade Federal do Piauí (UFPI).

${ }^{17}$ Ex-ministro do STF, professor titular da USP, doutor em direito econômico, professor visitante da Faculdade de Direito da Université de Montpellier e da Faculdade de Direito da Université Paris 1. ${ }^{18}$ Professor de Direito Constitucional, Doutor e Mestre em Direito do Estado pela PUCSP e Presidente da Sociedade Brasileira de Direito Constitucional (SBDC). 
mo Dallari ${ }^{19}$. Com tais sustentáculos da atual ciência jurídica, é muito difícil levantar a hipótese de que a tese de Ronaldo Jorge Araujo Vieira Junior seja ultrapassada ou mesmo lesiva à modernidade.

Ainda nesta pauta, é possível buscar uma fonte externa que reforce a sabedoria dos ditames postos em nossa Constituição. As palavras do Sumo Pontífice João XXIII na Encíclica Mater et Magistra, ao analisar a Encíclica Rerum Novarum de seu predecessor Leão XIII, afirmou:

“O Estado, cuja razão de ser é a realização do bem comum na ordem temporal, não pode manter-se ausente do mundo econômico; deve intervir com o fim de promover a produção duma abundância suficiente de bens materiais, 'cujo uso é necessário para o exercício da virtude' (S. Tomás, De Regimine Principum), e também para proteger os direitos de todos os cidadãos, sobretudo dos mais fracos, como são os operários, as mulheres e as crianças. De igual modo, é dever seu indeclinável contribuir ativamente para melhorar as condições de vida dos operários" (JOÃO XXIII, 1979, p. 11).

É claro que nesta relação: Capital internacional, trabalhador brasileiro e consumidor brasileiro, os dois últimos são os mais fracos. Portanto, proteger o país de uma possível dominação do sistema de produção, não parece ser uma atitude retrógrada ou démodé. Muito menos está indo na contramão da preservação dos empregos e qualidade de vida da população.

Ainda maior contundência traz o Art 170 da CF/88;

Art. 170. A ordem econômica, fundada na valorização do trabalho humano e na livre iniciativa, tem por fim assegurar a todos existência digna, conforme os ditames da justiça social, observados os seguintes princípios:

I - soberania nacional;

II - propriedade privada;

III - função social da propriedade;

IV - livre concorrência;

V - defesa do consumidor;

\footnotetext{
${ }^{19}$ Professor Emérito da Faculdade de Direito da Universidade de São Paulo e professor catedrático da UNESCO na cadeira de Educação para a Paz, Direitos Humanos e Democracia e Tolerância.
} 
A Constituição é clara, a atividade econômica tem por finalidade atender ao homem, e não o capital estrangeiro e para isto deve inicialmente respeitar a Soberania nacional. Respeitando a propriedade privada, mas esta impregnada na sua essência pela função social da propriedade. Permitindo a livre concorrência, com normas que coíbam a verticalização monopolista das cadeias produtivas, pois estas destroem o equilíbrio da livre concorrência. Focando, como maior beneficiário deste processo, o último elemento da cadeia do agronegócio, o ser humano consumidor.

Neste caminho da análise de interesses econômicos é saudável suscitar a teoria de Eggertsson sobre como as mudanças econômicas são promovidas pelos grupos de interesse. Tal teórico salienta a existência de dois tipos de movimentos que visam pressionar governantes, legisladores ou departamentos governamentais por mudanças nas leis e regulamentos para favorecimento próprio. $\mathrm{O}$ primeiro grupo é denominado de Rent-Seekers e são

\begin{abstract}
grupos de interesse que trabalham no sentido negativo aos mercados, de modo a estabelecer sistemas que, embora menos produtivos e socialmente ineficazes, são rentáveis aos membros do grupo. Para tanto, eles lançam mão de sua influência política, social e financeira (lobby) para manter (ou criar) um status institucional ou legal que favoreça (ou mantenha) a sua atividade, ou que evite uma redução de sua atuação econômica menos eficiente (SCOTON, TRENTINI, 2012).
\end{abstract}

Este grupo, com sua mobilização, promove ganhos ao seu círculo interno mesmo que a custo de prejuízos ao seu entorno social e dependentes de suas atividades.

O segundo grupo, os Profit-Seeking, atuam promovendo o sentido positivo do mercado. Neste quadro o agronegócio funciona com uma melhor distribuição dos rendimentos ao longo da cadeia do agronegócio e distancia-se do monopolismo vertical almejado pelo capital apátrida de investimentos.

Recorrendo ao histórico dos pareces sobre a aquisição de imóveis rurais por estrangeiros residentes e empresas autorizadas a funcionar no Brasil e seus equiparados, encontra-se o Parecer $n^{\circ}$ GQ - 22, de 1994, do então Advogado-Geral da União, Dr. Geraldo Quintão, atuante em uma filosofia neoliberal e de participação decisiva na batalha judicial das privatizações.

Diante deste fato histórico e da teoria econômica dos grupos de interesse, é plausível o questionamento sobre o fato do Parecer n ${ }^{\circ}$ GQ - 22, de 1994 estar isento de influências do processo neoliberal reinante neste período da história.

Convém resgatar que o Parecer CGU/AGU No 01/2008 - RVJ não é simplesmente uma imposição das restrições à aquisição de imóveis rurais às empresas brasileiras de capital estrangeiro controlador, mas sim uma construção 
demonstrando que a tese do Parecer $n^{\circ}$ GQ - 22, de 1994, estava errada em confirmar a inconstitucionalidade do $\S 1^{\circ}$, do art. $1^{\circ}$, da Lei 5.709/71. Segundo o novo parecer o citado parágrafo nunca perdera sua validade junto à Carta Constitucional, com ou sem revogação do seu Art. 171. Esta afirmação é construída por Ronaldo Jorge Araujo Vieira Junior resgatando o método teleológico de interpretação e preservando uma visão holística do texto constitucional, que lembra o Ex-ministro Eros Grau ao citar que "a Constituição não se interpreta em tiras, aos pedaços".

Este Parecer, que provocou tais mudanças na aquisição de terras por capital estrangeiro, está em consonância com a Constituição Federal e, portanto, devido a unicidade que caracteriza a nossa Carta Magna, também contribui com a preservação dos outros direitos que a permeiam.

Respeitar a Soberania é sim muito importante, tanto que a Lei 7.170/83, que prevê os crimes que lesam e expõem a perigo de lesão a integridade territorial e Soberania nacional, em seu Art. $9^{\circ}$ descreve como crime tentar submeter o território nacional, ou parte dele, ao domínio ou à Soberania de outro país. Determinando para tal crime uma pena de reclusão por 4 a 20 anos.

\section{CONSIDERAÇÕES FINAIS}

O caso em estudo não se refere à dominação especificamente por outra nação, mas sim pelo conjunto de investimentos apátrida denominado, fundos de investimento. Porém, o resultado e suas consequências para a população brasileira serão os mesmos. Assim, diante do dinamismo que o direito precisa ter para continuar a ser a égide que protege a sociedade, talvez se faça necessária uma alteração nesta Lei para clarear que ela também deve proteger a nação brasileira da tentativa de invasão do capital estrangeiro e punir justamente os, infelizmente, brasileiros que tentam enterrar os sonhos de um país livre e justo para todos ao venderem a sua dignidade e seu conhecimento para este consórcio de capitais.

Portanto, entende-se ser desnecessário para economia brasileira investimento em compras de terras por capital externo e é salutar para a Nação a preservação da Soberania ao coibir os excessos do capitalismo na aquisição de terras por estrangeiros.

\section{REFERÊNCIAS}

ARAÚJO, M. J. Fundamentos do agronegócio. 2. ed. ver. São Paulo: Atlas, 2007. p. 160.

BAUMAN, Z. Capitalismo parasitário. Rio de janeiro: Zahar, 2009. p. 92. 
BODIN, J. Les six livres de La République. Paris: Le livre de Poche, 1993. p. 111.

BRASIL. Ministério da Agricultura, Pecuária e Abastecimento (MAPA). Disponível em: <http://www.agricultura.gov.br>. Acesso em: 05 fev. 2012.

. Ministério do Desenvolvimento Agrário. Instituto Nacional de Colonização e Reforma Agrária. Incra qualifica informações sobre imóveis rurais em nome de estrangeiros no País. Disponível em: <http://www.incra. gov.br/index.php/noticias-sala-de-imprensa/noticias/13135-incra-qualificainformacoes-sobre-imoveis-rurais-em-nome-de-estrangeiros-no-pais $>$. Acesso em: 05 jun. 2013.

. Setores da economia: agronegócio. Disponível em: $<$ http://www. brasil.gov.br/sobre/economia/setores-da-economia/agronegocio $>$. Acesso em: 05 ago. 2012.

. Parecer - 01/2008-RVJ CGU/AGU. In: GODOY, A. S. de M.; RODRIGUES JUNIOR, O. L. (Org.). Coletânea de Manifestações da Consultoria-Geral da União - v. 1. Brasília, 2012. Disponível em: $<$ http:// www.agu.gov.br/sistemas/site/TemplateTexto.aspx?idConteudo $=171677 \&$ orden acao $=16 \&$ id_site $=7530>$. Acesso em: 05 jan. 2013.

DANI, F. A.; ÁlVARO, B. de O.; BARROS, D. S. O desenvolvimento sustentável como ótimo de Pareto na relação entre os princípios constitucionais ambientais e os princípios constitucionais econômicos. Revista de Direito Econômico e Socioambiental, Curitiba, v. 1, n. 2, p. 303-329, jul./dez. 2010.

HITCHENS, C. O julgamento de Kissinger. Tradução Giancarlo Summa. São Paulo: Boitempo, 2002. 192 p.

JOÃO XXIII. Carta encíclica Mater et Magistra: sobre a recente evolução da questão social. Rio de Janeiro: Vozes, 1979. p. 64.

LIBANIO, J. B.; MURAD, A. Introdução à teologia: perfil, enfoques, tarefas. 5. ed. São Paulo: Loyola, 2005. p. 217.

MALUF, S. Teoria geral do estado. 19. ed. São Paulo: Sugestões Literárias, 1988. p. 388.

NÓBREGA, M. Imóveis rurais e soberania nacional. Revista Veja, 06 mar. 
2012. Disponível em: <http://ptnosenado.org.br/textos-do-guia-de-leitura/89guia-de-leitura/12113-imoveis-rurais-e-soberania-nacional-mailson-da-nobregaveja>. Acesso em: 20 mar. 2012.

OLIVEIRA, L. P. P. da S. A soberania frente à globalização. Revista do Programa de Mestrado em Direito do UniCEUB, Brasília, v. 2, n. 1, p. 202 225, jan./jun. 2005.

REALE, M. Teoria do direito e do estado. 5. ed. São Paulo: Saraiva, 2000.

REZEK, J. F. Direito internacional público: curso elementar. 11. ed. rev. São Paulo: Saraiva, 2008.

ROSENFIELD, D. L. Hermenêutica ideológica. O Estado de São Paulo, São Paulo, 30 ago. 2010. Disponível em: <http:/www.estadao.com.br/noticias/ impresso,hermeneutica-ideologica,602347,0.htm>. Acesso em: 04 jun. 2013.

SCOTON, L. E. B.; TRENTINI, F. A lei 5.709/71 e as restrições à aquisição de propriedades rurais por pessoas jurídicas de capital estrangeiro: uma análise econômico-institucional. In: CONGRESSO ANUAL DA ASSOCIAÇÃO MINEIRA DE DIREITO E ECONOMIA, 4., 2012, Belo Horizonte. Revista da AMDE. Disponível em: <http://www.revista.amde.org.br/index.php/C2012/ article/view/188/126>. Acesso em: 19 jan. 2013.

SIMÕES, B. C. A Soberania revisitada: Carl Schmitt, Foucault e a questão do poder. In: RAMOS, F. C.; MELO, R.; FRATESCHI, Y. Manual de filosofia política: para os cursos de teoria do estado e ciência política, filosofia e ciências sociais. São Paulo: Saraiva, 2012. p. 229-257.

TEIXEIRA, M. M. P. A educação científica sob a perspectiva da pedagogia histórico-crítica e do movimento c.t.s. no ensino de ciências. Ciência \& Educação, v. 9, n. 2, p. 177-190, 2003.

TENDLER, S. Globalização Milton Santos - O mundo global visto do lado de cá, 2006. Disponível em: <http://www.youtube.com/watch?v=-UUB5DW_ mnM>. Acesso em: 01 ago. 2012.

TOYODA, H. A apologia dos direitos humanos e a razão perversa do capitalismo: do sujeito de direitos à falácia das garantias. Revista de Direito Econômico e Socioambiental, Curitiba - PR, v. 1, n. 2, p. 333-366, jul./dez. 2010 . 


\section{NATIONAL SOVEREIGNTY AND RURAL PROPERTIES}

ABSTRACT: Globalization, a phenomenon that emerged at the end of the twentieth century as a result of the capitalist system dynamism to generate new and large markets, provides a full integration in the political, social, cultural and economic. Therefore, this is the crucial aspect to the system. In this context, there is the formation of stateless capital conglomerates, always solicitous to investments in developing countries. These investments aim to take over the coordination downstream and upstream of the supply chains, especially in agribusiness. The Sovereignty in the current form, according to the advocates of these investments is a barrier to entry of foreign capital for the purchase of agricultural land and may compromise the Brazilian development, impairing the generation of employment and income. However, economic and legal arguments compelling, prove not need capital inflows for investment in the form of purchase of agricultural land. This paper hopes to present the reasons of flexibility of defenders on the purchase of agricultural land in Brazil for foreign capital and support an economic and legal opposition to this flexibility.

KEYWORDS: Globalization; Sovereignty; Purchase of agricultural land.

\section{SOBERANÍA NACIONAL E INMUEBLES RURALES}

RESUMEN: La globalización, fenómeno que surgió al final del siglo XX, como resultado del dinamismo del sistema capitalista al generar nuevos y grandes mercados, proporciona integración global en los aspectos políticos, sociales, culturales y económicos. Siendo esta última faceta determinante para el sistema. En este contexto, se observa la formación de conglomerados de capital apátrida, siempre solícitos a inversiones en los países en desarrollo. En estas inversiones se buscan asumir la coordinación y el montante de las cadenas productivas, especialmente en el agro negocio. La soberanía en los moldes actuales, según los defensores de estas inversiones, es un obstáculo a la entrada de capitales extranjeros para compra de tierras agrícolas y puede comprometer el desarrollo brasileño, perjudicando la generación de empleo y renta. Todavía, argumentaciones económicas y jurídicas contundentes, comprueban que no existe necesidad de la entrada de capitales para inversiones en la forma de compra de tierras agrícolas. Esa investigación ha buscado presentar las justificativas de los defensores de la flexibilización sobre la compra de tierras agrícolas en Brasil por capital extranjero y cimentar una contraposición económica y jurídica a esta flexibilización.

PALABRAS CLAVE: Globalización; Soberanía; Compra de tierras agrícolas. 